\title{
A thermal performance parametric study of window type, orientation, size and shadowing effect ${ }^{\sqrt{2}}$
}

\author{
Ana Rita Amaral ${ }^{\mathrm{a}}$, Eugénio Rodrigues ${ }^{\mathrm{a}, *}$, Adélio Rodrigues Gaspar ${ }^{\mathrm{a}}$, Álvaro Gomes ${ }^{\mathrm{b}}$ \\ ${ }^{a}$ ADAI, LAETA, Department of Mechanical Engineering, University of Coimbra \\ Rua Luís Reis Santos, Pólo II, 3030-788 Coimbra, Portugal \\ ${ }^{b}$ INESC Coimbra, Department of Electrical and Computer Engineering, University of Coimbra \\ Rua Luís Reis Santos, Pólo II, 3030-290 Coimbra, Portugal
}

\begin{abstract}
Windows are one of the elements that greatly influence the performance of buildings, both in terms of thermal comfort and energy consumption for heating or cooling. It is therefore important to find an optimal design that balances their orientation, dimension and shadowing. This paper presents a methodology for the parametric study of a window optimal dimension, based on the thermal performance of a reference room located in the climate region of Coimbra, Portugal. First, the parameters of opening type, orientation, and size are evaluated. During a second stage, the impact of using overhangs is assessed, with one of the most common window types in Portugal. The thermal assessment is carried out by calculating the degree-hours of discomfort using dynamic simulation. Results show that for this location, triple glazing has better performance than single and double glazing, especially for the north orientation. The worst opening orientation is northeast and northwest, independent of the window type. It is observable that optimum window dimension does not imply equal space cooling and heating needs. Results also demonstrate that overhangs do not significantly improve the room's thermal performance but allow windows to have a wider interval of admissible sizes without compromising performance.
\end{abstract}

Keywords: thermal comfort, dynamic simulation, window performance, window-to-floor ratio 


\section{Introduction}

Design decisions taken during the early architectural design phase may significantly contribute to a building's energy performance. From all building aspects, and due to materials intrinsic characteristics, windows play an important role in buildings' thermal performance. They are the weakest element, as the glazed areas still present the highest values of heat transfer coefficient (U-value) when compared to elements of the opaque envelope. Despite this, large glazing areas have been widely used in modern and contemporary architecture, either for aesthetic purposes or visual comfort. In this sense, if an inappropriate area or type of glazing may negatively impact heat gains or losses, an incorrect shadowing may contribute to an inefficient use of solar radiation, which can affect the thermal comfort of the occupants and increase the energy consumption for HVAC systems.

Several studies have already focused on the impact of how windows contribute to buildings' thermal and energy performance. The main challenge thus far has been to increase insulation properties in glazing systems and as a result, these have evolved from single pane to double, double with vacuum gap, gas, aerogel and more recently, to triple pane Ghoshal \& Neogi, 2014). In this sense, several authors conducted extensive literature reviews that assemble diverse aspects that may influence the global performance of a window, such as glazing type, fenestration products and materials, spacers, frames, air or gas gap between glass layers in glazing systems, and so on (Jelle et al., 2011; Cuce \& Riffat, 2015; Hee et al., 2015). More recently, new studies have demonstrated the advantages of incorporating new technologies, such as electrochromic windows to better control heat gains in east or west oriented openings (Tavares et al., 2014), the use of phase change materials in the transparent areas of buildings' envelope (Silva et al., 2016), or the use of a ventilation channel for exhausting air through windows from outside to inside or vice-versa, according to the climate season (Zhang et al., 2016). These efforts to increase a windows' performance by decreasing U-values and solar heat gain coefficients allow technicians today to choose from a wide

\footnotetext{
${ }^{\text {is }}$ Partial results of this study were presented in the Energy for Sustainability 2015 Conference, Sustainable Cities: Designing for People and the Planet, 14-15th May, 2015.

${ }^{*}$ Corresponding author.

Email address: eugenio.rodrigues@gmail.com (Eugénio Rodrigues)
} 
range of solutions according to specific architectural projects' needs. Indeed, several systems of window labelling have been studied, so that these may be applied as an autonomous product capable of ensuring specific levels of energy performance based on heating and/or cooling needs (Trzaski \& Rucinska, 2015). Nevertheless, these perspectives place the focus of thermal and energy performance merely on the development of new technologies, without considering the window size and orientation as a passive design measure. This has, actually, been gaining recognition amongst architects. Despite the availability of several assessment tools to predict gains and losses through windows, namely the use of dynamic simulation tools (Foucquier et al., 2013); estimations based on long-term measured climate data Kull et al. 2015); or the quantification of energy flows through glazing according to the orientation and local climate (Manz \& Menti, 2012), with regards to the study of dimension, placement or orientation of glazing areas, there is still much to be studied (Kontoleon, 2015).

Moreover, the use of triple glazing is not yet consensual. For instance, Tahmasebi et al. (2011) compared the thermal performance of double and triple glazed windows and concluded that triple glazing contributes to the reduction of annual energy consumption in all quadrants and in different Window-to-Floor Ratios (WFR). On the other hand, Gasparella et al. (2011) emphasise the fact that triple glazing windows show low solar transmittance, which in winter seasons can contribute to the reduction of solar gains that can overcome the reduction of thermal losses and increase energy needs. In addition, Zhang et al. (2016) performed a thermal evaluation of a double and a triple glazing window for a given location based on the calculation of total daily solar heat gains, and concluded that the heat losses are considerably reduced in winter with triple glazing, but the difference in heat gains in summer between the two glazing types are very low. Therefore, the selection of the glazing types must be preceded by a further analysis of their impact according to the geographical location and respective climate conditions.

With regards to shading devices, a detailed study is needful, due to their benefits in the reduction of potential solar heat gains and in execution costs. Overhangs and fins represent non-mechanic shading devices whose implementation can be considered as low cost when compared to automated shadowing (Bojić, 2006), such as adaptive building envelope devices 
(Zawidzki, 2015). However, when designing solar shadings, thermal and visual comfort may conflict (David et al., 2011). Some tools have been developed to optimise solutions for glazing areas according to illumination, glare, solar radiation, or visual comfort Andersen et al., 2008); however, shading devices seem to result from natural lighting concerns rather than due to thermal comfort or energy efficiency issues. When focusing on these issues, dynamic simulation tools are used to predict gains and losses through windows (Foucquier et al. 2013), and to assess the effect of overhangs in energy savings (Bojić, 2006; Ebrahimpour \& Maerefat, 2011). Nevertheless, all of these studies make use of a predefined window dimension and the mere possibility of having an overhang, a side fin, both or none, without analysing the influence of the windows and overhangs dimensions.

The design of shading devices with an adequate dimension and position and how these elements may be adapted to window performance needs is still a challenge for architects. Even though, this adaptation is desirable as it would increase solar heat gains in winter and decrease them in summer, while still providing a homogeneous distribution of daylight throughout the year (Kirimtat et al., 2016). Currently, overhangs are designed for aesthetics issues rather than for a conscious solar protection method. In this sense, it is important to achieve an easy and intuitive means to obtain the optimum overhang for each opening.

From the literature survey, it was apparent that research has mainly focused on advances in window technologies and products. However, the present study differs by proposing an approach that congregates several aspects including glazing type, window size, orientation and shadowing, taking into consideration that climate location and building systems provide specific conditions, potentially leading to different results. The overall purpose is to assist practitioners, namely architects, to take informed decisions in the early phase of the design process, by providing data in terms of thermal performance of windows and respective overhangs. This assessment was made in an annual, orientation quadrant, and seasonal basis.

This paper is structured in five sections. This first section introduces the subject matter and explains its importance. It also reviews the literature and past contributions to the field. The second section explains the used methodology. The third section presents the 
results before discussing them in the fourth one. Finally, the paper is concluded.

\section{Methodology}

Generative methods have been used to create large synthetic datasets. The analysis of these datasets allows us to better understand the building performance phenomena (Granadeiro et al., 2013, Rodrigues et al., 2015). The methodology used in the present work follows a procedure where in the first stage a reference room was created with a window placed in one of the widest exterior walls. Then, the room was replicated 180 times and rotated in such a way that the window faced a specific orientation in a two degree step. In the second stage, a parametric evaluation was carried out by incrementally testing every window dimension. This latter stage was carried out three times, once for every window type. The information was stored and used to create the reference room performance curve for every orientation. Each curve denoted the relation between the thermal performance and the window size. By determining the minimum value on the performance curve, it was possible to identify the optimum window dimension for a specific orientation and window type. By gathering all optimum curve points (one point per orientation) it was possible to draw the ideal performance curve of window sizes around $360^{\circ}$ degrees.

Finally, in the last stage, and for the most common window type in Portugal, the optimum overhang depth was determined for every window dimension and orientation. The optimum overhang depth was found by incrementally assessing the overhang depth in equal step intervals. When the reference room obtained a worse performance, the search stopped and recorded the last best depth value.

The main purpose was to achieve the optimal window size for a given space, with and without a passive shading mechanism, according to the location and orientation.

\subsection{Reference room}

The methodology used in the present study began by considering a thermal space as a reference room with fixed dimensions and predefined constructive systems. Figure 1 illustrates the geometry of the reference room, as well as the window position in the widest 
wall and the overhang to be analysed. Starting with an opening width of $0.01 \mathrm{~m}$ and a height of $2.00 \mathrm{~m}$, this will increase in size until it reaches all the available wall length, which means $7.00 \mathrm{~m}$ wide, thus having a WFR ranging from 0 to 0.614 . In addition, the opening orientation was analysed in a two-degree step around the $360^{\circ}$, starting at $0^{\circ}$ (north) and then turning east. For each window size step $(w)$ the optimum overhang depth $(d)$ was determined and it had the same width as the window.

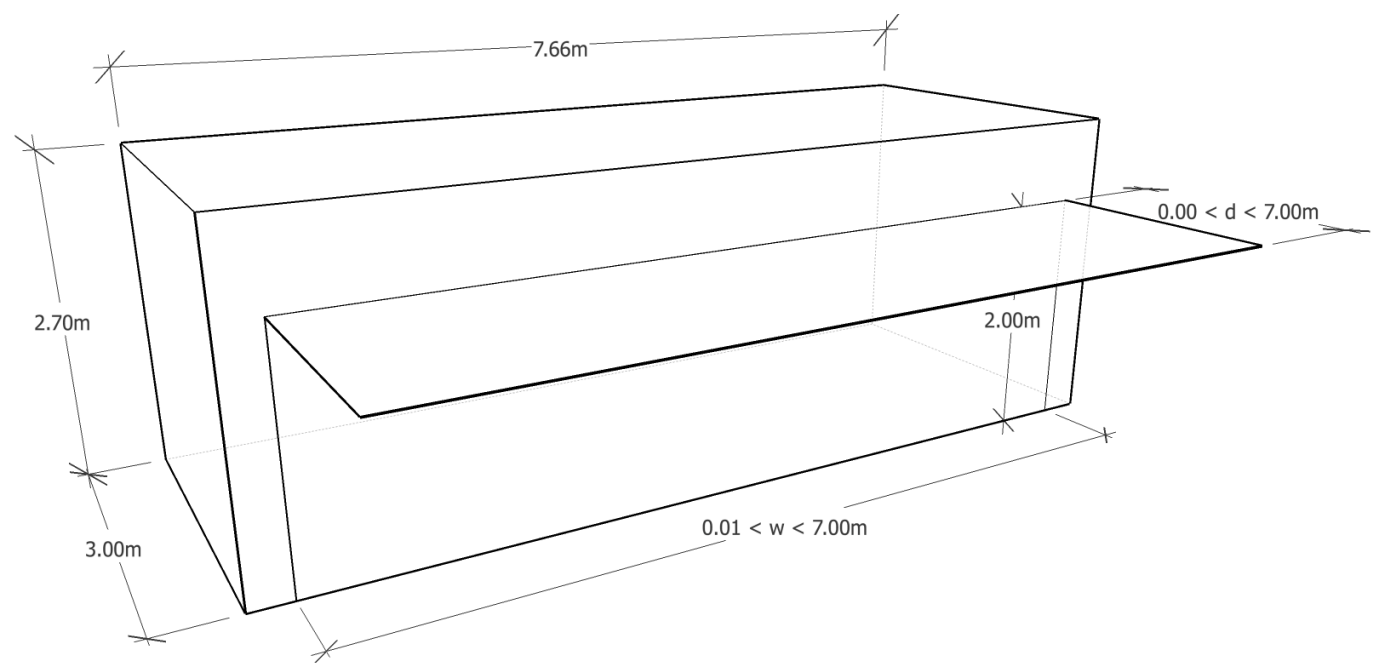

Figure 1: Geometry of the reference room. The window width (w) varies between 0.01 and $7.00 \mathrm{~m}$ and the overhang depth (d) between 0 and $7 \mathrm{~m}$.

The envelope constructive system corresponds to a typical Portuguese building and is presented in Table1 by the U-values for the floor, roof, and exterior wall elements. The physical properties of each material layer are also listed. Three glazing physical properties were chosen to characterise Single (SGW), Double (DGW), and Triple Glazing Window (TGW) with 5.70, 2.60, and 1.00 U-values respectively (see Table 2). The window was modelled as a simple window object where the U-value corresponded to the thermal transmittance of the whole window including glazing and framing.

The room was considered to have no occupation and no other internal gains from equipment or lighting. This was done in order to obtain a baseline space thermal behaviour. As the room was modelled not to have any occupation, the openings were set as being closed at all times. However, infiltration through cracks in the construction was considered as a 
Table 1: Physical properties of materials for each constructive system element.

\begin{tabular}{|c|c|c|c|c|c|c|c|c|c|}
\hline Element & U-value & $\begin{array}{l}\text { Layer } \\
(\mathrm{cm})\end{array}$ & $\begin{array}{c}\text { Th } \\
(\mathrm{W} / \mathrm{m}-\mathrm{K})\end{array}$ & $\begin{array}{c}\lambda \\
(\mathrm{kg} / \mathrm{m} 3)\end{array}$ & $\begin{array}{c}\rho \\
(\mathrm{J} / \mathrm{kg}-\mathrm{K})\end{array}$ & Sp & TA & SA & VA \\
\hline \multirow{5}{*}{ Exterior wall } & \multirow{5}{*}{0.43} & Plaster & 2.0 & 0.43 & 1250.0 & 1088.0 & 0.90 & 0.60 & 0.60 \\
\hline & & Dense brick & 11.0 & 1.25 & 2082.4 & 920.5 & 0.90 & 0.93 & 0.93 \\
\hline & & Insulation & 8.0 & 0.04 & 32.0 & 836.8 & 0.90 & 0.50 & 0.50 \\
\hline & & Concrete block & 15.0 & 1.73 & 2242.6 & 836.8 & 0.90 & 0.65 & 0.65 \\
\hline & & Plaster (gypsum) & 2.0 & 0.22 & 950.0 & 840.0 & 0.90 & 0.60 & 0.60 \\
\hline \multirow{4}{*}{ Ground Floor } & \multirow{4}{*}{0.45} & High weight concrete & 20.0 & 1.73 & 2242.6 & 836.8 & 0.90 & 0.65 & 0.65 \\
\hline & & Insulation & 8.0 & 0.04 & 32.0 & 836.8 & 0.90 & 0.50 & 0.50 \\
\hline & & Lime plaster & 2.0 & 0.80 & 1600.0 & 840.0 & 0.90 & 0.50 & 0.50 \\
\hline & & Hardwood & 1.5 & 0.20 & 825.0 & 2385.0 & 0.90 & 0.78 & 0.78 \\
\hline \multirow{5}{*}{ Roof } & \multirow{5}{*}{0.37} & Slag & 1.5 & 1.44 & 881.0 & 1673.6 & 0.90 & 0.55 & 0.55 \\
\hline & & Felt and membrane & 1.0 & 0.19 & 1121.3 & 1673.6 & 0.90 & 0.75 & 0.75 \\
\hline & & Dense insulation & 10.0 & 0.04 & 91.3 & 836.8 & 0.90 & 0.50 & 0.50 \\
\hline & & High weight concrete & 20.0 & 1.73 & 2242.6 & 836.8 & 0.90 & 0.65 & 0.65 \\
\hline & & Plaster (gypsum) & 2.0 & 0.22 & 950.0 & 840.0 & 0.90 & 0.60 & 0.60 \\
\hline
\end{tabular}

Table 2: Physical properties of windows.

\begin{tabular}{lclll}
\hline Element & U-value & Type & SHGC & VT \\
\hline \multirow{2}{*}{ Window } & 5.70 & Single Glass & 0.66 & 0.70 \\
& 2.60 & Double Glass & 0.63 & 0.56 \\
& 1.00 & Triple Glass & 0.51 & 0.42 \\
\hline \multicolumn{2}{l}{ SHGC - solar heat gain coefficient; VT - visible transmittance } \\
\hline
\end{tabular}

steady 0.4 air changes per hour.

\subsection{Thermal performance assessment}

The thermal performance assessment was based on the degree-hours method. The degreetime interval - which can be degree-hour, degree-day or degree-month - is a measure that reflects the amount of energy needed to heat or cool a space, by summing the difference between a running temperature-hourly, daily or monthly, according to the degree-time interval applied - and a reference temperature of comfort limit. The simple and accurate estimation provided by this method makes it widely used in diverse areas, such as HVAC 
industries or in energy planning (Satman \& Yalcinkaya, 1999).

In this case study, the thermal comfort assessment was calculated with a cost function (Eq. (1) that sums the total degree-hours of thermal discomfort (TDH) in the reference room. The heating degree-hours $(\mathrm{HDH})$ - which captures the heating needs - and cooling degree-hours $(\mathrm{CDH})$ - which measures the cooling needs - were determined by obtaining the difference between the operative indoor temperature and the adaptive thermal comfort limits, lower and upper bounds respectively, for naturally ventilated spaces, according to the European Standard 15251:2007.

Accordingly, the adaptive thermal comfort approach provided by this Standard was employed, which states that occupants tend to adapt to changing conditions in indoor environment, such as increasing or decreasing clothing layers, or even opening or closing windows (de Dear \& Schiller Brager, 2001, Nicol \& Humphreys, 2002). It is known that the conventional thermal comfort approach based on Fanger's models of Predicted Mean Vote and Percentage of People Dissatisfied draws a special attention to human contribution, mainly dependent on metabolic rates, clothing indexes, or even the occupants' distance to the window (Lyons et al., 2000; Singh et al., 2008). However, it is out of the scope of the presented study; thus, thermal comfort is assumed as related to the amount of energy needed to heat or cool a space, by comparing an operative temperature given by the room conditions and the reference temperature limits. It is not considered the variables that depend on a hypothetical human occupation, still it is taken into account, even indirectly, the radiation influence in each surface by the dynamic simulation model.

According to Eq. (1), the higher the value calculated, the worse thermal performance the space has. In it, $N_{t}$ is the number of hours in the year, $T(t)$ is the operative temperature at the time $t$, and $f_{d h}$ is the function that calculates the difference between the hourly operative temperature $T(t)$ and the thermal comfort limits $\left(T_{\text {lower }}(t)\right.$ and $T_{\text {upper }}(t)$, lower and upper limit respectively) according to Eq. (2).

$$
f(I)=\sum_{t=1}^{N_{t}} f_{d h}\left(T(t), T_{\text {lower }}(t), T_{\text {upper }}(t)\right)
$$




$$
f_{d h}\left(T, T_{\text {lower }}, T_{\text {upper }}\right)= \begin{cases}T_{\text {lower }}-T & \text { if } T_{\text {lower }}>T \\ T-T_{\text {upper }} & \text { if } T>T_{\text {upper }} \\ 0 & \text { otherwise }\end{cases}
$$

The operative temperature in the reference room was obtained by using a dynamic simulation program (EnergyPlus 8.1.0). The considered weather data was for Coimbra, Portugal, retrieved from the US Department of Energy website. This city, with a latitude of $\mathrm{N} 40^{\circ}$ $12^{\prime}$, longitude $\mathrm{W} 8^{\circ} 25^{\prime}$ and an altitude of $140 \mathrm{~m}$, has a cool-summer Mediterranean climate with dry warm summers and mild winters, according to the Köppen Geiger classification (Kottek et al., 2006). The climate is characterized by warm and dry summers with an average monthly temperatures bellow $22^{\circ} \mathrm{C}$ during it warmest month. In the coldest month of the year the average vary between -3 and $18^{\circ} \mathrm{C}$. Figure 2 depicts maximum, minimum, and the daily average temperatures in each month. Coimbra climate has a total of 414 annual cooling degree-days and 1297 heating degree-days for a baseline of $18.3^{\circ} \mathrm{C}$.

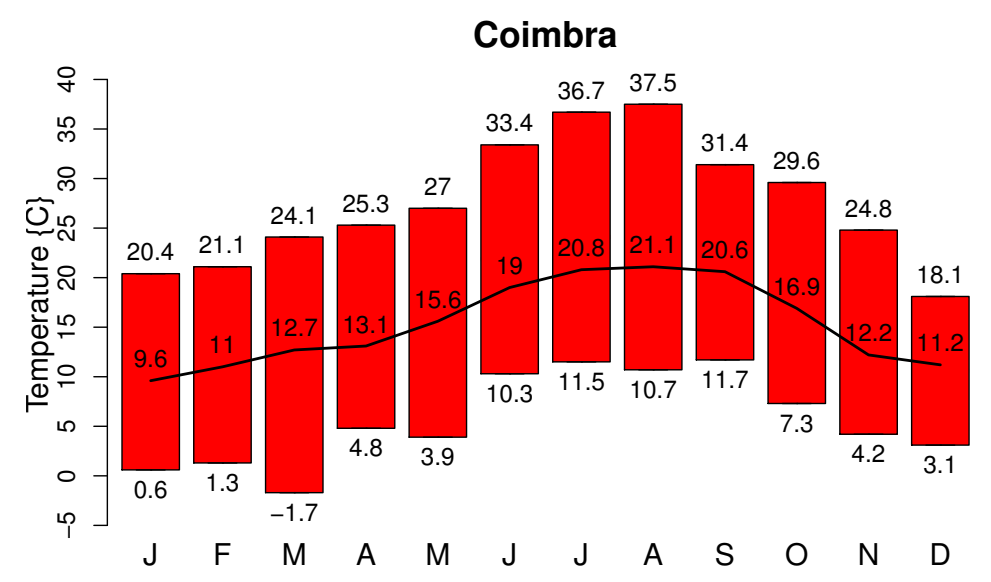

Figure 2: Maximum, minimum, and daily average temperatures for the climate region of Coimbra.

\subsection{A parametric approach}

In this parametric study two algorithms were used and specifically adjusted for this task. The EPSAP (Evolutionary Program for the Space Allocation Problem) algorithm consists in a hybrid evolutionary strategy approach enhanced with a local search technique to allocate 
rooms on a floor plan (Rodrigues et al. 2013a b c). This algorithm was used to generate a reference room with an opening in one of the larger exterior walls. This reference room is replicated 180 times with a different orientation in a two degree step interval.

The second algorithm, FPOP (Floor plan Performance Optimisation Program), is used to assess and alter the opening and overhang geometry. This algorithm consists in a sequential variable optimisation procedure, where different building geometry variables, such as the openings orientation, position and size, are changed, with the aim of minimising the total degree-hours of thermal discomfort (Rodrigues et al., 2014a b). The thermal performance of each solution is estimated using EnergyPlus (version 8.1.0). A database connected to both algorithms stores several constructive systems, with the physical properties of materials, as well as weather data and location information.

For each window type, the size of the window, which starts with $0.01 \mathrm{~m}$, is incrementally changed until it reaches $7.00 \mathrm{~m}$ wide. The room's thermal performance assessment is carried out at the end of each transformation and degree-hours of thermal discomfort are calculated. This results in three datasets - one dataset per window type - with the room performance for every orientation and window size. After, for the most common window type in Portugal, the process repeats and the optimum overhang depth is determined for each opening size step. The optimum overhang depth is found by incrementally testing the overhang depth until the room performance ceases to improve.

Therefore, two batches of simulations were carried out. The first one was used to determine the size and orientation for each window type having totalised 76140 simulations runs. The second batch involved more than 25380 simulations.

\section{Results}

\subsection{Comparison of glazing window types}

From the methodology described above, it was possible to obtain annual and seasonal assessment for each orientation and window type. In Figure 3 (a video with the optimum window sizes for all orientations can be found in the URL), each column corresponds to a 
window type (SGW, DGW, and TGW) and each row is one of the four main orientations (north, east, south, and west). In each graphic, the left-axis represents the relative thermal performance - the value 0 indicates the performance of a space without any opening and value 1 is the best performance in all orientations. The top and bottom axis represent the WFR and Window-to-Wall Ratio (WWR), respectively. The blue line denotes the relation between the window relative performance (delta TDH) and its size (WFR and WWR). As the performance assessment measures the amount of thermal discomfort, the minimum value on the performance curve is the optimum performance for that specific orientation. Gathering all optimum curve points (one point per orientation), the ideal performance curve is drawn around $360^{\circ}$ degrees (thin black line). The red line is the $\mathrm{CDH}$ divided by the TDH, whose scale is represented by the right-axis. The dotted lines are the other window types' optimum values for all orientations. The vertical grey line indicates the graph orientation.

As the window increases in size, independently of the window type, the room performance tends to improve until it reaches a minimum value (optimum window dimension) and then gets worse again (blue line). In the first part of the curve, the room performance improves due to the reduction of heating needs $(\mathrm{HDH})$. In the second part, the curve performance worsens due to overheating $(\mathrm{CDH})$ and heat losses through the window surface. The overheating may be confirmed by watching how the red line progresses, which indicates the ratio of CDH per TDH.

A general observable aspect in Figure 3 is an unexpected behaviour in the north quadrant for all window types. These have a higher WFR than in any other orientation. From a detailed analysis of the heat gains and losses, the sky diffuse radiation gain is higher than the heat transfer losses through the window surface. This thus allows for the use of larger windows without overheating due to beam solar radiation. 

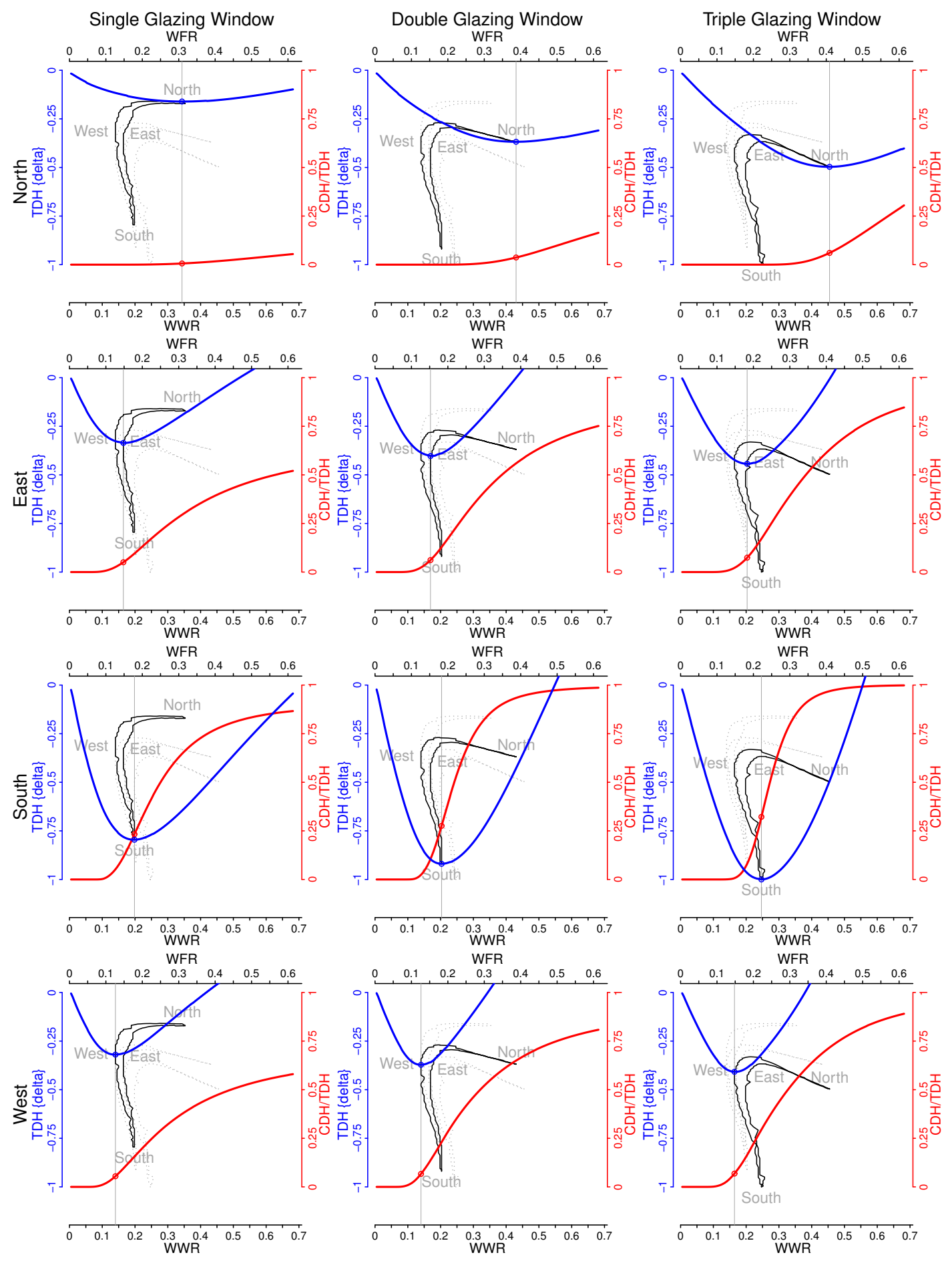

Figure 3: Annual assessment according to window type, orientation, and size. The blue line indicates the room performance and the red line indicates the ratio of $\mathrm{CDH}$ per TDH. The thin black line corresponds to the optimum window size (minimum value in each blue line) for all orientations. The dotted lines represent the other window types' optimum performance. 
In the case of the DGW and TGW, the performance is better than surrounding orientations (northeast and northwest). In the case of TGW, north orientation is even better than east and west opening orientations. The reason for this behaviour is the fast increase of overheating in east and west orientations due to solar beam radiation gains. As expected, the ratio of $\mathrm{CDH}$ per $\mathrm{TDH}$ is much higher in these orientations (red line). Still, this ratio is far from representing half of TDH in any quadrant, thus denoting that the heat losses through the window surface are higher than the solar heat gains.

The three window types have almost the same WFR in the south orientation, however, the performance increases with the number of window glazing.

Therefore, it is noticeable that TGW has the best performance in all orientations as it has the lowest performance curve (thin black line). The advantage of this window type is especially evident when the opening is facing the north quadrant.

When the annual thermal assessment broken-down into seasonal evaluations, it is noticeable that each window type has a significantly different behaviour. Figure 4 depicts the optimum performance for each season (rows) and each window type (columns) for the $360^{\circ}$ degrees orientation (black line).

During wintertime, except for the south quadrant for all window types and the north orientation for SGW, windows tend to have the best performance if they completely fill the exterior wall. This results from the fact that heat balance is positive due to sky diffuse radiation gains are higher than the losses through the window surface, as previously mentioned. During spring, the performance curves of all window types tend to flatten, especially for west, east, and south orientations. This means that, independent of the orientation, the performance does not vary much. In summertime, due to outside daily average temperature is within the thermal comfort limits (August, the warmest month, has $21.1^{\circ} \mathrm{C}$ daily average temperature) and the room's inertia, the window does not improve the thermal performance of the room and after a certain dimension the window even worsens the performance by overheating the space. Finally, in the autumn season there is a clear performance distinction between west and east quadrants, which does not occur in other seasons. 

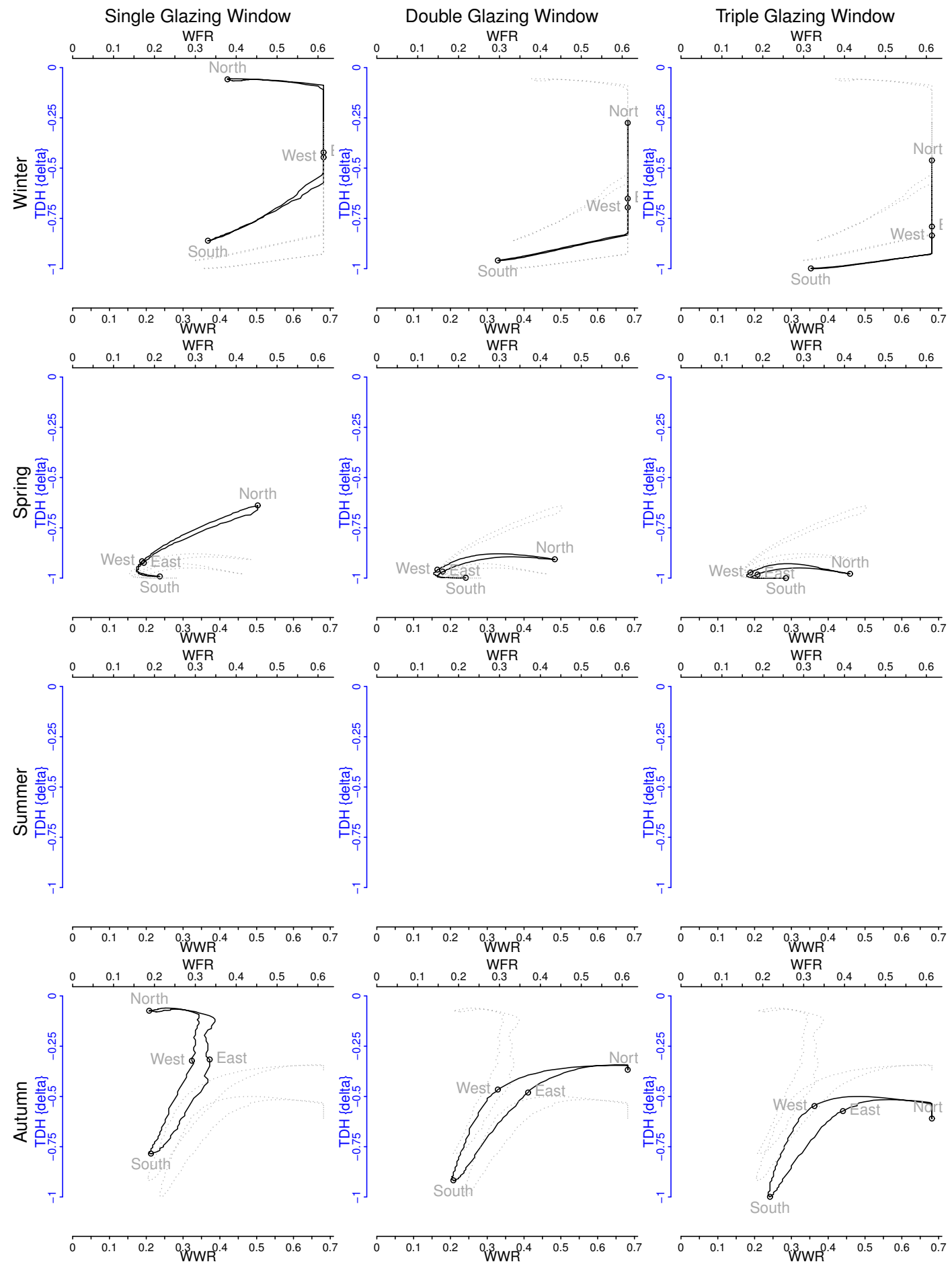

Figure 4: Seasonal assessment according to window type, orientation, and size. During summertime window size does not improve the room's thermal performance and, see Table 3 , may even worsen the room performance due to overheating when windows are too large. The thin black line corresponds to the optimum window size for all orientations in that specific season. The dotted lines represent the other window types' optimum performance. 
Table 3 resumes the intervals of optimum WFR for an annual assessment, a quadrant annual assessment, and a seasonal assessment. It is observable that WFR varies greatly, for example DGW has an interval of optimum WFR between 0.126 and 0.387 . This behaviour is even stronger when the assessment is seasonal. In wintertime, the WFR tends to increase to fill the available wall area (WFR of 0.614), and in the case of summertime, as explained before, the opening could even be absent, as it does not improve the space performance. The room thermal performance does not improve for having any window type during this season, however WFR may go up to 0.165, 0.196, and 0.240, respectively SGW, DGW, and TGW, before the performance worsens for the space due to overheating.

Table 3: WFR optimum interval per window type for Coimbra region.

\begin{tabular}{|c|c|c|c|c|c|}
\hline Type & Annual & & Quadrant & & Season \\
\hline SGW & $0.126-0.318$ & $\begin{array}{l}\text { north } \\
\text { east } \\
\text { south } \\
\text { west }\end{array}$ & $\begin{array}{l}0.170-0.318 \\
0.148-0.200 \\
0.152-0.178 \\
0.126-0.170\end{array}$ & $\begin{array}{l}\text { Winter } \\
\text { Spring } \\
\text { Summer } \\
\text { Autumn }\end{array}$ & $\begin{array}{c}0.331-\mathbf{0 . 6 1 4} \\
0.157-0.453 \\
0.165^{*} \\
0.187-0.348\end{array}$ \\
\hline DGW & $0.126-0.387$ & $\begin{array}{l}\text { north } \\
\text { east } \\
\text { south } \\
\text { west }\end{array}$ & $\begin{array}{c}0.178-0.387 \\
0.152-0.231 \\
0.152-0.183 \\
0.126-0.178\end{array}$ & $\begin{array}{l}\text { Winter } \\
\text { Spring } \\
\text { Summer } \\
\text { Autumn }\end{array}$ & $\begin{array}{c}0.296-\mathbf{0 . 6 1 4} \\
0.139-0.435 \\
0.196^{*} \\
0.183-\mathbf{0 . 6 1 4}\end{array}$ \\
\hline TGW & $0.148-0.409$ & \begin{tabular}{|l} 
north \\
east \\
south \\
west
\end{tabular} & $\begin{array}{c}0.222-0.409 \\
0.178-0.265 \\
0.187-0.231 \\
0.148-0.222\end{array}$ & $\begin{array}{l}\text { Winter } \\
\text { Spring } \\
\text { Summer } \\
\text { Autumn }\end{array}$ & $\begin{array}{c}0.318-\mathbf{0 . 6 1 4} \\
0.161-0.413 \\
0.240^{*} \\
0.213-\mathbf{0 . 6 1 4}\end{array}$ \\
\hline
\end{tabular}

* Summer does not have any thermal discomfort up to this WFR value. Bold text indicates the maximum WFR admissible value.

When windows' performance is analysed on a seasonal basis, it is observable that the WFR variation in winter and autumn is even greater than in the annual analysis. The behaviour is different in the springtime and summertime. In the case of TGW, the performance is similar in any orientation in spring. 


\subsection{Contribution of overhangs}

This approach also allowed to determine the optimum overhang depth for each window size and orientation. The DGW was selected for a detailed analysis of the results, as it is the most common type of glazing used in Portugal. This methodology may however be applicable to the other glazing types.

Figure 5 shows the results for the DGW with the contribution of an overhang in eight orientations (north, northeast, east, southeast, south, southwest, west, and northwest). A new right-axis in green was added and represents the relative overhang depth (1 is equal to $7.00 \mathrm{~m}$ depth). The green line denotes the relation between the window dimension (WFR or WWR) and the optimum overhang depth for that window size. Therefore, the performance curve (blue line) differs from Figure 3 due to the benefit of the overhang. This may be read in the graphics, as the green line increases, the space overheating (CDH, red line) is attenuated thus flattening the blue line from that point. As the performance curves have different minimum points, the 360 degrees curve (thin black line), which captures the optimum window sizes, also changes.

As shown, the overhang does not contribute to the thermal performance in the north quadrant, as the main contribution is from solar diffuse radiation and only when the WFR is greater than 0.55 does the overhang have some effect. Similarly, in northeast and northwest orientations the overhang is also unnecessary. However, in both cases, if the window is slightly bigger than 0.23 and 0.18 WFR (northeast and northwest respectively), the overhang may contribute to reduce $\mathrm{CDH}$.

Nevertheless, the behaviour is different for orientations ranging from east to west passing through south. In these orientations, as the overhangs increase (green line) these reduce or attenuate the overheating (red line). This allows a higher optimum WFR. For instance, in the south orientation the optimum size without overhang is near $0.18 \mathrm{WFR}$, however, with a shading mechanism it is above 0.35 WFR. From all orientations, the west and east are the ones that require the larger overhangs ( 0.30 and 0.25 relative depth respectively). 

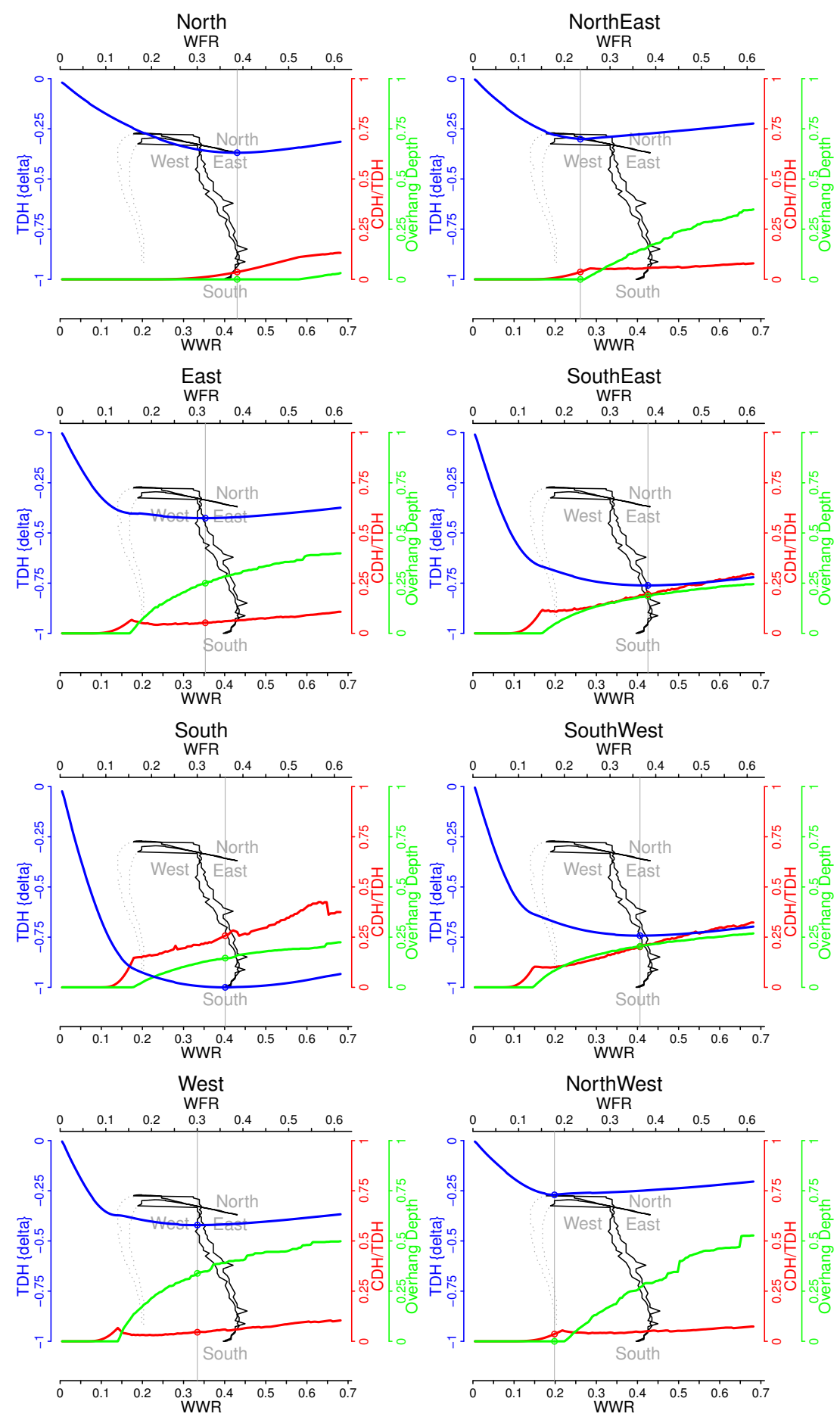

Figure 5: Overhang contribution for the Double Glazing Window according to the orientation. The blue line indicates the room performance and the red line indicates the ratio of $\mathrm{CDH}$ per TDH. The green line indicates the overhang depth ratio. The thin black line corresponds to the optimum window size (minimum value in each blue line) for all orientations. The dotted line corresponds to the optimum window size without overhang. 


\section{Discussion}

The present study aims to propose a simple way of analysing and assessing the optimal dimension of windows and respective overhangs, according to a given building system, orientation and climate location. For this, a generation, evaluation and optimisation procedure was carried out, in order to obtain information on the thermal performance in an annual, seasonal and quadrant basis. The results, in the form of WFR, were analysed taking into consideration the space thermal comfort performance (TDH), as well as the relative amount of overheating $(\mathrm{CDH} / \mathrm{TDH})$. For both variables, the lower value corresponds to the best performance.

When considering the design of a window based on its permanency characteristics, the annual assessment may provide the most adequate overview. However, due to the significant differences between seasonal and annual results achieved in this study, one would recognise that an in-depth study by season is indeed valuable for any building with seasonal occupation.

Even a slight variation in WFR, as shown in Figure 3, for the same window type and orientation, may lead to significant different results in terms of overheating or thermal discomfort, especially in the south quadrant, followed by west and east. Therefore, obtaining the precise value corresponding to the optimum window dimension may make a huge difference.

As expected, TGW presented the best performance amongst the analysed glazing systems, for the studied climate location. As shown, different window glazing types have different optimum window sizes. In other words, each window type has its own optimum opening geometry. Therefore, when retrofitting old buildings, if the window type is changed, the opening dimensions may also have to be altered to obtain the optimum thermal performance benefit of the new window type.

As previously stated, the DGW was selected for the study of overhangs, as it is the most common glazing type used in Portugal. Figure 5 presents the results for four more orientations, and it is evident that the worst opening orientation is northeast and northwest, 
even with the help of an overhang. Despite this, the main interest in this analysis is the comparison between the results of WFR with and without overhangs. When comparing these, it was noticeable that overhangs significantly contributed to the improvement of the thermal performance in the reference room for the west, south, and east quadrants, by allowing the increase of the WFR. However, based solely on the thermal comfort criteria, and taking into account that the main contribution of the overhangs to the thermal performance is the reduction of the cooling needs, the overall improvement is not so significant when compared to a well-dimensioned window (when comparing the dotted black line and the continuous black line in the graphics).

The heterogeneity in the set of optimum WFR is also noticeable, as well as the variability in the amount of the overheating curve (red line), when comparing with the results from the DGW without overhang, confirming that a slight variation in the WFR may lead to significantly different performances. Thus, it is possible to state that shading mechanisms allow the building designer to explore larger window areas or to use shading devices as corrective measures to over-dimensioned openings. This is especially evident in east and west orientations, where the thermal performance (strong blue line) is almost horizontal.

\section{Conclusions}

Despite not considering other performance requirements, such as lighting conditions and visual comfort, it is possible to understand how window type, size, and orientation have a significantly different impact on a building's thermal performance.

For this particular case study, it was also possible to conclude that large glazing areas facing north are not particularly bad for the thermal performance, since gains through sky diffuse radiation compensate possible thermal losses. However, the benefits are almost none in the case of windows with low thermal resistance. In relation to seasonal assessment, it is evident that WFR vary greatly. From wintertime, where window size tends to be the largest possible, to summertime, where even the existence of the opening is dispensable, the space performance varies significantly and an ideal opening WFR is difficult to determine, as a single value may hide different thermal behaviours around the year. 
In a global way, it is known that different types of glazing perform differently in diverse orientations. However, through this approach, it is possible to obtain the minimum values of penalties for all orientations. This means that it is possible to consider the optimal window size in new buildings, according to orientation, climate location and the building's physical properties. Thus, if a practitioner considers the most adequate glazing type in the early phase of the design process, either for new or existing buildings, alternative solutions may be adopted to improve the buildings' energy and thermal performance in the subsequent operations phase. Moreover, this analysis may be beneficial when designing windows in buildings with seasonal occupation, whether in winter or summer.

The presented methodology allows a simple and intuitive assessment of buildings systems, namely openings, providing useful data that can help architects and decision makers to obtain the window size with less thermal penalties for each case and, especially, a precise depth for the studied shadowing. This is particularly important in the early phase of the design process, as it aims to help in the adequate incorporation of those shading devices in the building design, or even to use them as a corrective mechanism for existing windows with suitable dimensions.

\section{Acknowledgements}

The presented work is framed under the Energy for Sustainability Initiative of the University of Coimbra (UC). Ana Rita Amaral and Eugénio Rodrigues acknowledge the support provided by the Portuguese Foundation for Science and Technology (FCT) under Doctoral grant PD/BD/113718/2015 and PostDoc grant SFRH/BPD/99668/2014, respectively.

\section{References}

Andersen, M., Kleindienst, S., Yi, L., Lee, J., Bodart, M., \& Cutler, B. (2008). An intuitive daylighting performance analysis and optimization approach. Building Research 8 Information, 36, 593-607. URL: http: / /www.tandfonline.com/doi/abs/10.1080/09613210802243159, doi:10.1080/ 09613210802243159

Bojić, M. (2006). Application of overhangs and side fins to high-rise residential buildings in Hong Kong. Civil Engineering and Environmental Systems, 23, 271-285. doi:10.1080/10286600600888532. 
Cuce, E., \& Riffat, S. B. (2015). A state-of-the-art review on innovative glazing technologies. Renewable and Sustainable Energy Reviews, 41, 695-714. URL: http://www.sciencedirect.com/science/ article/pii/S1364032114007710, doi/10.1016/j.rser.2014.08.084.

David, M., Donn, M., Garde, F., \& Lenoir, a. (2011). Assessment of the thermal and visual efficiency of solar shades. Building and Environment, 46, 1489-1496. URL: http://dx.doi.org/10.1016/j. buildenv.2011.01.022, doi 10.1016/j.buildenv.2011.01.022.

de Dear, R., \& Schiller Brager, G. (2001). The adaptive model of thermal comfort and energy conservation in the built environment. International Journal of Biometeorology, 45, 100-108. doi:10.1007/ s004840100093.

Ebrahimpour, A., \& Maerefat, M. (2011). Application of advanced glazing and overhangs in residential buildings. Energy Conversion and Management, 52, 212-219. URL: http://dx.doi.org/10.1016/ j.enconman.2010.06.061, doi 10.1016/j.enconman.2010.06.061.

Foucquier, A., Robert, S., Suard, F., Stéphan, L., \& Jay, A. (2013). State of the art in building modelling and energy performances prediction: A review. Renewable and Sustainable Energy Reviews, 23, 272-288. doi $10.1016 /$ j.rser.2013.03.004.

Gasparella, A., Pernigotto, G., Cappelletti, F., Romagnoni, P., \& Baggio, P. (2011). Analysis and modelling of window and glazing systems energy performance for a well insulated residential building. Energy and Buildings, 43, 1030-1037. URL: http://linkinghub.elsevier.com/retrieve/pii/ S0378778811000053, doi $10.1016 / j . e n b u i l d .2010 .12 .032$.

Ghoshal, S., \& Neogi, S. (2014). Advance Glazing System - Energy Efficiency Approach for Buildings a Review. Energy Procedia, 54, 352-358. URL: http://linkinghub.elsevier.com/retrieve/ pii/S1876610214011552, doi:10.1016/j.egypro.2014.07.278.

Granadeiro, V., Correia, J. R., Leal, V. M., \& Duarte, J. P. (2013). Envelope-Related Energy Demand: A design indicator of energy performance for residential buildings in early design stages. Energy and Buildings, . URL: http://linkinghub.elsevier.com/retrieve/pii/S0378778813000947. doi $10.1016 /$ j.enbuild.2013.02.018.

Hee, W., Alghoul, M., Bakhtyar, B., Elayeb, O., Shameri, M., Alrubaih, M., \& Sopian, K. (2015). The role of window glazing on daylighting and energy saving in buildings. Renewable and Sustainable Energy Reviews, 42, 323-343. URL: http://linkinghub.elsevier.com/retrieve/pii/S136403211400793X. doi $10.1016 /$ j.rser.2014.09.020.

Jelle, B. P., Hynd, A., Gustavsen, A., Arasteh, D., Goudey, H., \& Hart, R. (2011). Fenestration of today and tomorrow: A state-of-the-art review and future research opportunities. Solar Energy Materials and Solar Cells, 96, 1-28. URL: http://linkinghub.elsevier.com/retrieve/pii/ S0927024811004685, doi $10.1016 / j . s 01 m a t .2011 .08 .010$ 
Kirimtat, A., Kundakci, B., Chatzikonstantinou, I., \& Sariyildiz, S. (2016). Review of simulation modeling for shading devices in buildings. Renewable and Sustainable Energy Reviews, 53, 23-49. URL: http: //dx.doi.org/10.1016/j.rser.2015.08.020 doi:10.1016/j.rser.2015.08.020

Kontoleon, K. (2015). Glazing solar heat gain analysis and optimization at varying orientations and placements in aspect of distributed radiation at the interior surfaces. Applied Energy, 144, 152164. URL: http://www.sciencedirect.com/science/article/pii/s0306261915001233. doi $10.1016 / j$.apenergy.2015.01.087.

Kottek, M., Grieser, J., Beck, C., Rudolf, B., \& Rubel, F. (2006). World Map of the Köppen-Geiger climate classification updated. Meteorologische Zeitschrift, 15, 259-263. URL: http://openurl.ingenta. com/content $/$ xref?genre=article\&issn=0941-2948\&volume=15\&issue $=3 \&$ spage $=259$ doi $10.1127 / 0941-2948 / 2006 / 0130$.

Kull, T. M., Mauring, T., \& Tkaczyk, A. H. (2015). Energy balance calculation of window glazings in the northern latitudes using long-term measured climatic data. Energy Conversion and Management, 89, 896-906. URL: http://linkinghub.elsevier.com/retrieve/pii/s0196890414009479. doi $10.1016 / j$.enconman.2014.10.058.

Lyons, P. R., Arasteh, D., \& Huizenga, C. (2000). Window performance for human thermal comfort. Transactions - American Society of Heating, Refrigerating and Air Conditioning Engineers, 106, 594604. URL: http://gaia.lbl.gov/btech/papers/44032.pdf.

Manz, H., \& Menti, U.-P. (2012). Energy performance of glazings in European climates. Renewable Energy, 37, 226-232. URL: http://linkinghub.elsevier.com/retrieve/pii/s0960148111003089. doi $10.1016 / j . r e n e n e .2011 .06 .016$.

Nicol, J. F., \& Humphreys, M. A. (2002). Adaptive thermal comfort and sustainable thermal standards for buildings. Energy and Buildings, 34, 563-572. doi 10.1016/S0378-7788(02)00006-3.

Rodrigues, E., Amaral, A. R., Gaspar, A. R., \& Gomes, A. (2015). How reliable are geometry-based building indices as thermal performance indicators? Energy Conversion and Management, 101, 561578. URL: http://linkinghub.elsevier.com/retrieve/pii/s0196890415005518, doi10. $1016 / j$.enconman.2015.06.011.

Rodrigues, E., Gaspar, A. R., \& Gomes, Á. (2013a). An approach to the multi-level space allocation problem in architecture using a hybrid evolutionary technique. Automation in Construction, 35, 482498. doi $10.1016 / j$.autcon.2013.06.005.

Rodrigues, E., Gaspar, A. R., \& Gomes, Á. (2013b). An evolutionary strategy enhanced with a local search technique for the space allocation problem in architecture, Part 1: Methodology. Computer-Aided Design, 45, 887-897. doi:10.1016/j.cad.2013.01.001.

Rodrigues, E., Gaspar, A. R., \& Gomes, Á. (2013c). An evolutionary strategy enhanced with a local search 
technique for the space allocation problem in architecture, Part 2: Validation and performance tests. Computer-Aided Design, 45, 898-910. doi 10.1016/j.cad.2013.01.003.

Rodrigues, E., Gaspar, A. R., \& Gomes, Á. (2014a). Automated approach for design generation and thermal assessment of alternative floor plans. Energy and Buildings, 81, 170-181. doi:10.1016/j.enbuild. 2014.06 .016 .

Rodrigues, E., Gaspar, A. R., \& Gomes, Á. (2014b). Improving thermal performance of automatically generated floor plans using a geometric variable sequential optimization procedure. Applied Energy, 132, 200-215. doi $10.1016 / j$.apenergy.2014.06.068.

Satman, A., \& Yalcinkaya, N. (1999). Heating and cooling degree-hours for Turkey. Energy, 24, 833-840. doi $10.1016 / \mathrm{S} 0360-5442(99) 00035-3$.

Silva, T., Vicente, R., \& Rodrigues, F. (2016). Literature review on the use of phase change materials in glazing and shading solutions. Renewable and Sustainable Energy Reviews, 53, 515-535. URL: http: //dx.doi.org/10.1016/j.rser.2015.07.201, doi:10.1016/j.rser.2015.07.201.

Singh, M. C., Garg, S. N., \& Jha, R. (2008). Different glazing systems and their impact on human thermal comfort-Indian scenario. Building and Environment, 43, 1596-1602. doi:10.1016/j.buildenv.2007. 10.004 .

Tahmasebi, M. M., Banihashemi, S., \& Hassanabadi, M. S. (2011). Assessment of the Variation Impacts of Window on Energy Consumption and Carbon Footprint. Procedia Engineering, 21, 820-828. doi 10 . $1016 / j$.proeng.2011.11.2083.

Tavares, P., Gaspar, A., Martins, A., \& Frontini, F. (2014). Evaluation of electrochromic windows impact in the energy performance of buildings in Mediterranean climates. Energy Policy, 67, 6881. URL: http://linkinghub.elsevier.com/retrieve/pii/s0301421513006812, doi10. $1016 / j . e n p o l .2013 .07 .038$.

Trzaski, A., \& Rucinska, J. (2015). Energy labeling of windows - Possibilities and limitations. Solar Energy, 120, 158-174. URL: http://www.sciencedirect.com/science/article/pii/ S0038092X15004004 doi:10.1016/j.solener.2015.07.029.

Zawidzki, M. (2015). Dynamic shading of a building envelope based on rotating polarized film system controlled by one-dimensional cellular automata in regular tessellations (triangular, square and hexagonal). Advanced Engineering Informatics, 29, 87-100. URL: http://linkinghub.elsevier. com/retrieve/pii/S1474034614000950, doi:10.1016/j.aei.2014.09.008.

Zhang, C., Wang, J., Xu, X., Zou, F., \& Yu, J. (2016). Modeling and thermal performance evaluation of a switchable triple glazing exhaust air window. Applied Thermal Engineering, 92, 817. URL: http://linkinghub.elsevier.com/retrieve/pii/S1359431115010054, doi10. $1016 / j$.applthermaleng.2015.09.080. 